\section{Improve removable partial dentures with innovation}

Solvay Dental 360 is transforming dentistry with Ultaire AKP - a custom-developed polymer specifically designed for the fabrication of removable partial dentures (RPDs). This innovative, high performance material is strong, durable and biocompatible as well as lightweight and completely metal free.

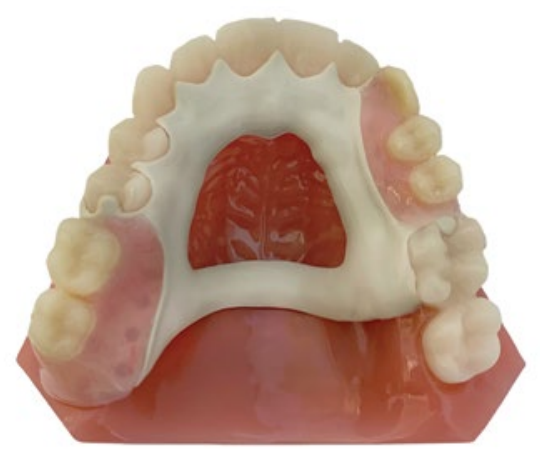

Ultaire AKP fits seamlessly into the digital workflow to create RPDs with improved accuracy so that your patients can enjoy better retention with increased comfort and fit. Visit the Solvay Dental 360 on stand J55 at the British Dental Conference \& Dentistry Show 2020 where industry experts can show you how.

To book a Solvay Dental 360 Professional Lunch and Learn or to find more information about Ultaire AKP and Dentivera milling discs, visit www.solvaydental360.com.

\section{The easy choice of interdental brush}

In a crowded market, choosing the right oral health products can be confusing for patients and practitioners supporting them.

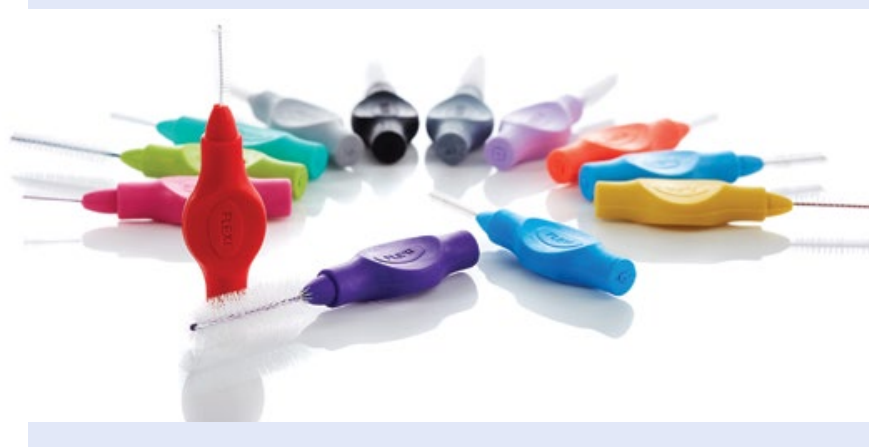

TANDEX is adding international standard ISO and PHD (passage hole diameter) numbers to the packaging of its FLEXI interdental brushes. This makes it easier to understand which brush is suitable for each user.

The ISO defines what PHD interval the brush can be squeezed into without deformation. PHD is based on the number of filaments per $\mathrm{cm}$, nylon thickness per $\mathrm{mm}$ and how hard the brush is twined.

It's a simple system and new for 2020. Find out more today!

For more information on Tandex's range of products, visit www.tandex.dk.

\section{An intelligent obturation material}

ROEKO GuttaFlow bioseal is an intelligent obturation material from COLTENE.

How can it upgrade your endodontic treatment? It will:

Fill and seal the root canal by combining free-flow guttapercha with sealer

- Provide natural repair constituents on contact with fluids

- Activate biochemical processes, supporting regeneration, especially of bone and dentine tissue

- Offer a short curing time and easy handling.

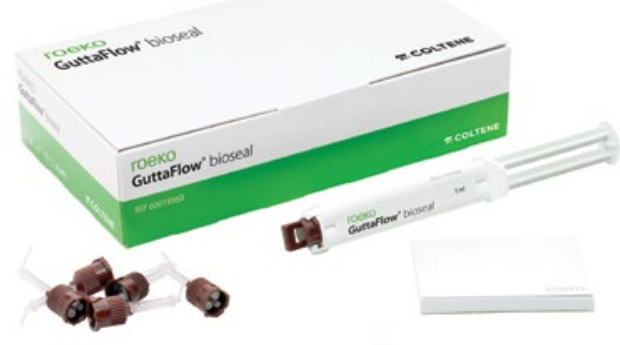

COLTENE leads the market in endodontic tools and materials. Each addition to the range is carefully developed before it is launched, so that once it's available it provides clinicians with just what they need for stable, successful outcomes.

It is time you discovered COLTENE?

To find out more visit www.coltene.com, email info.uk@ coltene.com or call 01444235486.

\section{Flowable bioactive composite}

Whether you wish to build up occlusal surfaces and anatomical details, or line cavity floors and fill occlusal or cervical cavities, the newly developed Beautifil Flow Plus X offers the optimal flowability and dimensional stability for all indications, since it is available in two viscosities: F00 (Zero Flow) and F03 (Low Flow). This injectable hybrid composite for anterior and posterior restorations builds on the clinically proven handling benefits of Beautifil Flow Plus; it is non-slumping, self-levelling and non-dripping. Besides, SHOFU's improved Giomer Technology with nano S-PRG filler particles enhances polishability, gloss retention and bioactivity - for sustainable, long-term protection against recurrent caries.

The composite is available in nine common tooth shades plus various dentine, enamel, bleach and effect shades, based on the shade range and featuring the proven shade stability of the entire Beautifil product line.

For further information contact Shofu - 01732 783580, sales@ shofu.co.uk, www.shofu.co.uk. 